\title{
A US model for inclusion of disabled students in higher education settings: the social model of disability and Universal Design
}

\author{
Heather Mole \\ McGill University, Canada \\ Email: heather.mole@mcgill.ca
}

\begin{abstract}
At a time when the consumer-student is choosing an education based on valuefor-money, disabled students will want to know that they have been considered in the campus design and included in the approach to learning. The new discourse of inclusion coming from disability service providers in higher education (HE) in the US centres on a 'universal design' (UD) approach. The cutting edge of service provision in the US focuses on incorporating the philosophy of the social model of disability and the tool for implementing it: universal design. Service providers are beginning to call themselves 'Resource Centres'; resources for students but also faculty, advising and collaborating on instructional methods that design students with disabilities into the classroom instead of directing them to write exams and receive accommodations in a separate location. This paper presents research undertaken in 2008 that explored the motivations and intentions of five universities in the US that claimed to be using a social model of disability service provision approach. It also examines the concept of universal design, and its relationship with the social model in this process, because it emerged as the dominant characteristic of these services. A qualitative questionnaire was distributed to the institutions, which explored the philosophical underpinnings to their service models and investigated the practical implications of those commitments. It focused on the tools that they used for implementation, particularly universal design, and the changes they made to their services in order to be consistent with the social model. An analysis of their responses highlighted emerging themes and key characteristics and identified problematic issues. The philosophy of UD encompasses diverse populations, benefits everyone in the classroom and aims for an inclusive learning environment. The model promotes inclusion and is, simultaneously, a selling point for consumers with diverse learning styles because it goes beyond the 'sage on a stage' approach.
\end{abstract}

Key terms: inclusive education; higher education; disability; social model of disability; universal design; diversity. 


\section{Introduction}

Higher education (HE) establishments around the world have different policies for providing accommodations to disabled students (Hurst, 1998). In the UK institutions for higher education are bound by the Equality Act 2010 to provide reasonable accommodations to disabled students, likewise in the United States they are bound by Section 504 of the Rehabilitation Act of 1973. Students must selfidentify as disabled and provide evidence to be eligible for the support services. This approach to service provision for disabled students assumes that environments will always have to be adapted and accommodations provided, rather than targeting the automatic incorporation of these elements into all aspects of the design of campus life. This can lead to alienating practices for these students. For example, in a study done on the perceptions of the accommodation process of disabled students in post-secondary education in a few HE institutions in the US, researchers found that $27.3 \%$ of the students asked did not find their exam accommodations to be effective (Kurth and Mellard, 2006). One student explained that his sense of belonging in the classroom was disrupted because the accommodation in exams was provided in a separate location from that of his peers. Although the accommodations provided to students may meet the requirements of the law and level the playing field, they do not always provide an inclusive environment.

Theoretical approaches in disability studies characteristically advocate moving from a 'medical' model to a 'social' model of disability (Barnes, 2000), but practice has not always kept pace with theory. Whereas the medical model situates the disability within the individual and sees them as the root of the problem to be cured or treated and normalised, the social model of disability positions the root of disability in society; it identifies social prejudices, inaccessible environments, discriminatory work arrangements and segregated education as disabling societal features (Oliver, 1996:32, 33). Within this model, disabled people are people with impairments (UPIAS, 1974/1976), who only become 'disabled' when they encounter a barrier in their everyday life - such as a set of stairs with no ramp for someone with a mobility impairment, or a book that is not offered in digital format for a person with a visual impairment. A social model of service provision in higher education would determine ways to make all aspects of university life accessible from the outset. In the current context, on the other hand, the very existence of a service for students with disabilities implies the existence of a need for accommodations; it implicitly suggests that there must be barriers that disabled students face. The logical outcome of this argument is that the very fact that services are trying to work from a social model is an oxymoron (Gibbs, 2004:158). Most services for disabled students in the US, and arguably elsewhere, work from a model in which accommodations are put in place retrospectively by necessity or legal requirement: 
The accommodation model of disability services is currently the most prevalent model in the postsecondary setting. Many disability service professionals would defend this model as a social model approach. When we explore it closely and compare it to the universal design approach, it is clear that it is more aligned with medical model thinking. (University of Arkansas at Little Rock, n.d.)

So, for example, where stairs were previously a barrier for a student using a wheelchair, there is now an alternate route involving a lift or ramp. Where exams are held in a large classroom and are considered time-sensitive, students with disabilities take their exams in another setting with appropriate technology and/or flexibility built into the time allocation. However, these modifications are retrofitted arrangements; implemented after an exclusive design has been imposed (McGuire, Scott and Shaw, 2003:10).

Table 1: Main elements of the accommodation approach and the UD approach

\begin{tabular}{|l|l|}
\hline Accommodation approach & Universal Design approach \\
\hline Access is a problem for the individual. & $\begin{array}{l}\text { Access issues stem from an inaccessible, } \\
\text { poorly designed environment and should be } \\
\text { addressed by the designer. }\end{array}$ \\
\hline $\begin{array}{l}\text { Access is achieved through } \\
\text { accommodations. }\end{array}$ & $\begin{array}{l}\text { The system/environment is designed, to the } \\
\text { greatest extent possible, to be usable by all. }\end{array}$ \\
\hline Access is retroactive. & Access is proactive. \\
\hline Access is exclusive/specialised. & Access is inclusive. \\
\hline Access is consumable. & $\begin{array}{l}\text { Access, as part of the environmental design, } \\
\text { is sustainable. }\end{array}$ \\
\hline
\end{tabular}

Adapted from AHEAD Universal Design Initiative Team (2004)

Table 1 shows the main elements of the accommodation approach based on a biomedical understanding of disability, requiring documentation from a medical professional before implementation. As we can see, the accommodation approach does not embrace the social model because of its focus on the individual as the problem. It requires students to identify as disabled; it also requires students to accept a different treatment than that received by their peers, and it compels them to manage their accommodations and submit to procedures that other students do not have to face. The process is necessarily retroactive and consumable as accommodations are provided repeatedly to individuals at a considerable cost. In order to work from a social model framework, this needs to be entirely reversed and people with disabilities need to be included at the design and implementation stages. A popular tool for implementing social model approaches to disability service provision in colleges and universities in the US is the concept of universal design (UD). UD is an architectural paradigm that provides seven principles of 
design. The purpose of these design principles is: 'The design of products and environments to be usable by all people, to the greatest extent possible, without the need for adaptation or specialized design' (The Center for Universal Design, 1997).

From 2000, this concept has become increasingly popular in professional development conferences for disability service providers in the USA (Block, Loewen and Kroeger, 2006) because it offers practitioners very tangible solutions that deliver outcomes readily matching the goals of the social model. The model has broadened its reach from the confines of architectural and product design to instructional and software design. It is being promoted as an approach to access on campus, in contrast to the accommodation approach.

Frank Bowe (2000), known in America as the father of Section 504, takes the principles of UD and applies them to the educational setting. He focuses not only on the physical environment but on instructional practices as well. He believes that UD can incorporate the majority of students from diverse backgrounds, including disabled students, leaving only a minority who will require special accommodations, thereby reducing the need for assistive technologies or at the very least making resources compatible with assistive technologies (Bowe, 2000). UD is a very attractive, marketable tool because it corresponds to a growing understanding that classrooms are becoming increasingly diverse (Burgstahler and Cory, 2008). Its application has an impact on a wider population than disabled students, especially students whose first language is not English (Embry et al., 2005). It also promises to reduce expenditure because it anticipates the high cost of retrofitting or providing individualised support after an inaccessible, though perhaps inexpensive, design has been installed (Burgstahler and Cory, 2008). There is some initial evidence that suggests that course completion rates of disabled students could dramatically improve when UD is introduced into the classroom (Jenner, 2008).

By looking again at Table 1 we can see the difference between the two approaches. Access issues become a problem stemming from the environment. Access is not achieved through accommodations but with the help of an inclusive design from the outset. It is now a proactive process; rather than specialised, it becomes inclusive for everyone and finally it becomes sustainable rather than an endlessly repeated expenditure of resources.

\section{Context}

In order to situate this research and provide a context, it is necessary to offer some historical background. When it comes to provision of service to people with disabilities in the US, HE institutions must obey two important laws: Section 504, subpart E of the Rehabilitation Act of 1973 and the Americans with Disabilities Act (ADA) of 1990 (Aune, 1998). If an educational opportunity is available to any student, then Section 504 states that it must be available to a disabled student as well (Jarrow, 1993). The ADA later ensured that not only public institutions 
were beholden to the law but private ones were too, raising further awareness about disability rights (Aune, 1998). Section 504 requires that an institution have an officer who ensures that the law is implemented and in some institutions it is an office for assessment and provision of accommodations. These include, for example, alternative test arrangements such as extended time, taking the test in a separate room, re-assignment of a class to an accessible location, course substitution, materials provided in alternative print (e.g. Braille, large print, tape disk) (Aune, 1998:189). Some of these are retrospective accommodations: for example, where a building is inaccessible, the programme must be moved rather than the building made accessible.

In a special issue of a student services journal (Kroeger and Schuck, 1993) published nearly 20 years ago, on disability service provision, the editors made explicit mention of the social model. Sue Kroeger and Judy Schuck (1993) incorporated the socio-political model (citing Hahn, 1985) into their analysis of provisions. Not only do they strongly assert that the social model is the way forward but they also begin to promote the idea of Universal design (UD):

We must make facilities and sites work for everyone, not just for a generic physical standard that really does not exist. We must go beyond minima to optima and institutionalize the concept of universal design by designing buildings, systems, procedures, and activities that everyone can use... We must stop thinking 'special', because the consequence of 'special' is 'separate'. (Kroeger and Schuck, 1993:105-106)

Kroeger and Schuck (1993) blend the ideas of inclusion and equality of access with the social model and envision the principles of UD as a tool for achieving the ideals of the social model. This model has gradually gained influence on HE in the US (Aune, 1998). This theme persists to the present day in articles published in the Association on Higher Education and Disability's (AHEAD) Journal of postsecondary education and disability, a main source of professional information and research for practitioners in this field. AHEAD was founded in 1977 and is the national professional association for people working in offices for students with disabilities. In 1992 it changed its name to AHEAD and, in 2012, it has over 2500 members, with international membership in 10 countries as well (AHEAD, 2004-2012). AHEAD holds an annual conference and papers given there have in recent years included subjects such as universal design and the social model of disability.

\section{The research project}

The intention of this research is to identify successful attempts at creating inclusive learning environments in $\mathrm{HE}$, in order to make recommendations to institutions and suggest further research. It will also identify the challenges faced by those 
trying to implement this approach and explore the evolving role of these services. The main research questions will be:

- How does the social model of disability approach to service provision unfold in each of the higher education contexts selected?

- What are the main issues and considerations arising from the adoption of a social model approach with disabled students within the sample?

- What challenges and successes have been experienced in the implementation of the social model approach in these institutions?

- How is universal design situated within these changes?

In order to answer the research questions outlined above, this study began by gathering existing literature and information from the web on the potential institutions in order to select universities and colleges that might fit the sampling criteria for the study. Once the three to five universities had been selected, a questionnaire on their specific adoption of the social model of disability and/or UD was administered. The results are analysed and the findings used to generate policy recommendations and implications to inform further research.

\section{Methods}

\section{Preliminary research}

The preparation of the questionnaire and the sampling method required an in-depth analysis of the literature. This included extensive web searches on the universities in the US operating a service for disabled students. Mission statements were scrutinised and related documents were read to determine the specific approach of each university. Similarly, literature on the approach of these services to service provision was read in order to determine the content of the questionnaire.

\section{Sampling}

In order to carry out the sampling, key informants were asked to identify institutions the stated aim of which is to work towards a social model of disability in their delivery framework. This non-probability criterion-based selection utilised network sampling (Mason, 2002; Punch, 1998). The key informant is experienced in the field and has visibility among professionals who work in the service provision sector. The informant is a proponent of the approach and is published in AHEAD's Journal on postsecondary education and disability. An initial consultation with the key informant revealed a list of six institutions that could have been eligible. The researcher identified another three institutions that were not in the informant's 
list; these were leads originating from the literature. There are weaknesses to this approach because using only one key informant will potentially bias the results as institutions outside of the network will not be considered (Bloch, 2004). However, the choice of implementing purposive sampling based on the reputation of institutions in this targeted study ensures a quick selection of institutions that match the criteria. Additionally, as three further institutions were added to the sample by the researcher, the potential for bias was lessened. A sample size of nine institutions allows for the possibility of non-participation, while aiming for successful data collection from at least 4-6 institutions. Ultimately, the participating institutions numbered five; four were recommended by the informant and one was yielded by further research. The respondents were directors of services for disabled students. The profiles of the universities that they serve are as follows:

- Respondent A serves a small, publicly funded, metropolitan southern university with a research-intensive focus.

- Respondent B serves a large, Midwestern university considered to be a 'Public-Ivy'.

- Respondent C serves a large, southern university considered to be a 'Public-Ivy'.

- Respondent D serves a medium-sized, state-funded, Midwestern university. It should be noted, however, that this office only serves students with physical and health-related disabilities and not students with learning or psychological disabilities, who have a separate service.

- Respondent E serves a medium-sized, private, Ivy League, East Coast university.

\section{Data collection}

Due to the geographical spread of the participants and cost implications a questionnaire was the data collection method selected. Collecting data through the use of a semi-directive questionnaire ensures consistency in data collection with each institution. The interviewer-effects and biasing errors are eliminated (Bloch, 2004) and only the wording of the questions could have an influence on the respondents' answers. There are limitations in using this approach because the respondent cannot easily clarify the question with the researcher if there is misunderstanding (Bloch, 2004). The researcher cannot probe for further information directly; however, the contact information for the researcher was available to the respondents. A script for the initial contact telephone interview, serving as an introduction, was developed as a guide. A similar introductory email was created if communication via the phone proved difficult. Email was 
the preferred means of communication of the participants, and in six cases email responses were received. Only two participants did not respond at all and a further participant was later reached by phone.

After the initial contact the directors were sent a link to an online questionnaire, hosted by Surveymonkey (www.surveymonkey.com). The questionnaire was designed to be both qualitative and quantitative and was semi-structured. Online delivery of the questionnaire was selected for various reasons: the tool was cheap and simple to use; it had the capacity to be delivered over a wide geographical range (Bloch, 2004); the questionnaire looked professional and allowed recipients to come back to it several times while offering them the possibility of saving data throughout; data collection and storage were secure; reminder emails could be sent to recipients individually. The format was easily manipulated by the researcher but ensured that the recipients could not alter the layout when responding. It was not deemed a disadvantage to use the web for this questionnaire, as the majority of universities in the US use the web to advertise themselves and therefore effectively operate administratively 'online'. It is also highly regular for all staff at a university to have their own email address. Surveymonkey has the facility to link a questionnaire to an email address, making it impossible for any other person to obtain knowledge about it or access the questionnaire independently. Therefore, for a response to come from someone other than the intended target, the respondent would have to give permission to another person knowledgeable about the service and then send them the link to the questionnaire. As most respondents emailed separately after they had completed the questionnaire, it is reliable to assume that the intended recipients answered the questionnaire personally; in one specific case, the recipient answered it with another member of the service sitting next to her/him, because the person felt that doing it together would produce fuller answers. Unfortunately, Surveymonkey is not an accessible web tool for screenreaders and therefore a separate word document was created and sent as an attachment for anyone requiring that format. The questionnaire was piloted with one institution before distribution. That institution gave feedback and the questionnaire was changed slightly before being sent to the other institutions. This ensured that terminology was understood and questions were clear. Self-report is also unreliable, though some external validation will be possible from publicly available resources and information from university websites already researched in an earlier stage of the study.

\section{Qualitative follow-up telephone interviews}

This was an opportunity to gather more qualitative data. Recording the data involved making extensive notes while on the phone. Respondent $\mathrm{C}$, one of the five who did not fully complete the questionnaire, was invited to discuss the issues in the questionnaire by telephone. As time was an issue and the respondent was in a 
unique position of understanding the terrain and organisationally at the professional association level, it was deemed more important to discuss her perceptions of the issues raised concerning the implementation of the social model and UD than to encourage her to complete the rest of the questionnaire.

\section{Size of study}

This research design only examined data collected in five institutions. There are limitations therefore on how much comparison can be made between the institutions and whether the identifiable trends have validity in a wider context. Time did not permit this study to include a larger number of institutions. The research objective is not to discover generalised patterns about the situation in US postsecondary educational institutions; it aims to explore what unit staff believe they are enacting and what motivations and principles underpin the actions they have taken.

\section{Findings and implications}

Some examples of the responses from the services follow as an illustration of the quality and depth of the data collection. Each of the participants understood the social model of disability and gave a brief description that correlated with the main tenets of the model, placing the problem of disability in society and not in the individual. Examples of their descriptions include:

B: 'an individual is only as disabled as the environment $\mathrm{s} / \mathrm{he}$ finds himself in. Environment includes physical, technological, programmatic and attitudinal.'

D: 'The social model is a new paradigm of disability. Disability is simply a difference. It reframes disability as a positive difference that one should be proud of. It reframes disability from an individual "problem" to a societal "issue" ... The social model enhances the development of self determination and disability pride.'

Each of the universities was able to describe the model in terminology consistent with it. Moreover, they all stated that the model was reflected in their service philosophy. On the question of how it had informed their service philosophy, each described different ways in which it manifested itself:

A: 'We have begun to promote our office as a collaborative office which works with students but also provides services to the campus at large and specifically to the designers of environments such as the IT environment, the online learning environment, the classroom or lab environment, etc. Viewing our services from this perspective has also resulted in our taking a hard look at the language that we use and work to eliminate words that reflect older, medical model thinking.' 
B: 'We look for ways to imbed access and accommodation into the broader context of usability. Advocating for captioning at significant campus events even where this accommodation has not been requested by a Deaf/HH person is an example.'

C: 'It has informed our mission, goals, job descriptions, service delivery procedures, programs, and professional development.'

D: 'We are striving to incorporate universal design in everything we do. I feel that this sets the tone that full access and participation for our campus community is everyone's responsibility; not just the [disability] office ...'

E: 'advocacy and role on campus in barrier removal both physical and other barriers ...'

The wide variety of answers, ranging from a very specific example by B to more generalised ideas such as those of $\mathrm{C}$, shows diverse visualisations of the social model in practice and perhaps varying depths in the interpretation of the model. We can also see a connection being made between the social model of disability and UD (by university D). There also appears to be a connection between theory and practical application. It is evident, from further questions, that the universities are seeing the social model in concert with UD, and that both of these concepts have simultaneously affected the changes in service philosophy that have occurred in recent years.

A: 'Universal design is a framework for thinking about environments that goes hand in hand with the social model of disability. The principles of universal design support the creation of products, services and environments that are usable by the widest range of users without modification or retrofitting.'

Respondents were also asked to comment on changes made in their services. Those aspects of service discussed included: language changes, number and type of services, disability documentation, interactions with students and faculty, impact on the built environment, influence on instructional materials and influence on wider university policies. Every service aspect mentioned in the questionnaire had been changed by a minimum of two of the five institutions, indicating that each of the aspects included in the questionnaire is relevant to the service philosophy change. Four of the five universities had reviewed the language used on their websites and publications. Two universities had increased their number of services to include consultation with faculty and staff on UD, and more services to faculty and nonregistered students. Three of the universities had changed their documentation practices to include more reliance on self-report and a minimum of documentation. Four universities have changed their interaction with students by reframing the way they talked about disability using the social model, by relying more on student report or by having a more individualised interaction. All the participants embrace the notion of educating, consulting or coaching faculty on topics such as more 
accessible instructional design and the diversity of learners in the classroom. Four universities observed that they had had an impact by way of consultation with facilities staff and recommending UD principles. Three universities believed that they had an influence on wider university policy and practices and a fourth hoped to in the future.

The data collection exercise was sufficient to produce a resource that enabled an analysis of the research questions. It also resulted in the identification of some emerging themes. One of the most significant findings was that the social model of disability appears to be implemented through the use of universal design principles. Each university in the sample blended these two concepts and established explicit connections between the two notions.

\section{Emerging themes}

\section{Changing language, changing concepts}

Three of the participating institutions felt that a need existed to review all of their literature and publications so that the language they used became consistent with that of the social model of disability and UD. This was identified as a key starting point for all of them. For one institution, it was particularly important as well to involve the unit staff in education and professional development around these concepts. This has had a 'powerful' effect on the students using their services according to the service providers,

A: 'Students have responded positively. Communicating with students in ways that reframe disability from the social model perspective has been particularly powerful.'

\section{Becoming a collaborator}

The next theme arising out of the data analysis is the need for disability services to transform their role within the university. This was described in various ways, including collaborating with university stakeholders, students, faculty and staff. This theme appears in the literature as well, advocating a broadening of the role of disability service providers, beyond service provision, to include a consultation role on UD across campus (Burgstahler, 2008a; Embry et al., 2005).

\section{Becoming an expert}

Alongside collaboration with people on campus, a new and important role was identified in the data as that of becoming an 'expert' on how to implement inclusion in all areas of university life. Where previously, the minimum workable amount of expertise a disability service provider would need was knowledge of the law and 
specific knowledge about disabilities and accommodations, these units are now realizing that they need to be experts in UD. Furthermore, they express the need for them to be strategic in the ways that they communicate their vision of inclusion as it impacts the whole campus and requires support from senior administrators.

\section{Decentralising}

Spreading the responsibility for access across the campus is another theme that transpires in the data. The decentralisation of service provision to disabled students, from the disability service office to the campus at large, is a radical shift in thinking. Where once Section 504 officers, exclusively, ensured compliance with the law, we are now seeing a revolutionary move towards global responsibility for access and inclusion. This, in turn, requires the disability service to engage fully with the university and creates new imperatives and burdens.

\section{Documenting disability}

The documentation of disabilities is clearly a requirement that sits uncomfortably with some of the universities taking part in this research. When promoting a social model that rejects over-medicalisation of the student, it seems paradoxical to ask for medical documentation as a condition to services. This contradiction is clearly debated in the literature, and disability studies scholars challenge the power of professionals or the use of medical diagnoses as the final word in matters relating to the provision of services:

The social model of disability questions the professional dominance over disability and supports experience over expertise, and self-help and collective action over professional intervention and personal adjustment. (Gillman, 2004:256)

As stakeholders in the assessment procedure the disabled student should be considered the best and most reliable source of information on their condition. There is an express drive, originating from the professional organisation AHEAD, to require minimal documentation and encourage instead that information be collected through the interview process with the student; this is considered 'primary documentation'. They also recommend that the determination of accommodations should be done in collaboration with the student, data collected in this way amounts to 'secondary documentation' (AHEAD, 2012). The emphasis has switched from medical documentation (or 'tertiary documentation') to the student's self-report. Furthermore, UD practices should lessen the need for students to register with the disability service. 


\section{Faculty endorsement}

Getting faculty endorsement for UD is a significant problem identified by the participants, because of the time commitment required to take the training and implement UD into their teaching and course design. This is not always a priority for faculty who have many existing responsibilities. There is some evidence that once UD training is offered the desire among faculty for more training increases (Finn et al., 2008). This concern about meeting resistance from faculty is corroborated in a study about service providers' perceptions of Universal Design for Instruction (UDI), in which a larger number of service providers were consulted (Embry et al., 2005).

\section{Funding}

Two service providers identified funding as a barrier to their continued promotion of the social model and UD. This concern is corroborated in the literature (Burgstahler, 2008c), and though the assumption is that introducing UD principles into HE environments will ultimately lower overall costs - because fewer individual accommodations will be necessary and retrofitting accommodations is usually highly expensive - there are some who suggest that there must be an injection of money to begin with.

\section{Student consultation}

A notable omission from the responses given in the questionnaires was consultation with disabled students. No service observed that the changes in their service philosophies had been prompted by disabled students, or reached through consultation with students; motivation for change was not linked to student input. This is a concern, especially as the students are the main stakeholders in the provision of these services and will be directly affected by the changes. A major focus of research in the field of Disability Studies has been user-led organisations of disabled people. The independent living movement in the US and centres for independent living in the UK have been prominent in the campaign to participate in and control the way they receive and utilise services and resources. In describing the characteristics of user-led services one scholar writes:

There is a broad consensus that user-led organizations offer a distinctive approach to service provision. This encompasses: adherence to a social model; democratic accountability; promoting independent/integrated living through widening user choices. And including all disabled people. (Mercer, 2004:179)

Many of the service units demonstrated a commitment to promoting disability pride, independence and self-determination in their mission statements; however this is not manifesting itself in a true commitment to student input and collaboration. 
There are two issues here that are being neglected by service providers: first, that by excluding students from the process, they are failing to follow their stated policy, and simultaneously losing an opportunity to educate and empower the disabled students they serve; second, that the voice of the students could lend significant weight to their petitions to the powers that be, within the institution, for wider access.

\section{Study limitations}

The research brought to light some of the key characteristics of the service model adhered to by disability providers; this study, however, was limited in its scope and in its ability to establish systematic triangulation. This was partly due to the restrictions imposed by time and resources and partly due to the lack of existing research on this emerging phenomenon.

\section{Sample}

The universities involved were targeted because their approach is aligned with a social model. This form of sampling does not lend itself easily to the generalisation of findings, but it does have clear benefits, one of them being that it generates richer, more descriptive data that enables the researcher to gain greater insight into this emerging phenomenon.

\section{Impact on students and faculty}

This research did not address the impact of the implementation of a new service approach on the students or the academic staff directly. It was also not possible to validate whether the reality for disabled students in HE in the US matches the interpretations of the service providers. Further research should focus on campus visits, student experiences and faculty responses. Some literature suggests that there is positive feedback coming from students (Behling and Hart, 2008), but it is mostly anecdotal evidence from professors. A chapter written by disabled students in a newly published book on UD states that ' $[\mathrm{m}]$ ost literature about the application of universal design to instruction has been written by researchers and practitioners' (Durre et al., 2008:83) but goes on to conclude:

Students with disabilities do not always agree on the best practices for UDI. Overall, however, they make it clear that universal design strategies represent good teaching practice and minimize the need for specific accommodations. (Durre et al., 2008:95)

There is a need for further research that might include consultation with disabled students. Despite the logical assumptions that this is the way forward for an inclusive agenda, that agenda must take account of those it wants to include. 


\section{Minimal research on impacts of UD}

Despite the emerging popularity of UD with disability service provision, there is a notable lack of research with regards to outcomes for stakeholders. This was expressed as a concern by one respondent in this study and is echoed in the literature (Finn et al., 2008; Burgstahler, 2008b; Embry et al., 2005). A leading researcher at the University of Connecticut, on the UDI Project Team, says of the current status of research:

A substantive question revolves around what to measure to determine the efficacy of UDI. We are particularly interested in academic self-efficacy as we believe that relates to the practice of including inclusive strategies in teaching. In terms of measuring learning outcomes, that becomes trickier because of intervening variables (e.g., student motivation, study habits, prerequisite knowledge, etc.). (McGuire, 2008, personal communication)

This uncertainty in the field has an impact on the practice because, without research to support it, UD has less explicit validity.

\section{Recommendations for disability service providers in HE}

One of the aims of this research was to provide recommendations to HE institutions that are hoping to reframe their services towards the social model. What follows are five recommendations that have materialised from this research, not as a definitive policy, but as steps to be considered during the developmental process:

1. Disability service staff should learn about disability studies, become familiar with the social model in particular but also gain a grasp of relevant areas of interest such as inclusive education and user-led organisations.

2. Disability services staff should familiarise themselves with the concept of UD and in the different manifestations that UD takes in an HE context (UDI, UDL, etc.) They should seek to become experts and act as resource centres. AHEAD is a useful point of reference in this process.

3. Services should involve the students registered with their service in the educational process that they themselves are undergoing. They should listen to the views and concerns of the students during this process and adapt their views in collaboration with these key stakeholders. They might consider creating an action plan for implementation in collaboration with disabled students and building some accountability into the process. 
4. Building networks in the university is a vital component of this process. Areas to focus on are collaborations with the faculty, teaching support services, administration at every level, facilities staff and information technology service. Educating people on campus about the new paradigm of disability and the concept of UD will sensitise people gradually to these concepts.

5. Reviewing and changing the literature and publications that are produced, as well as the language used when communicating with stakeholders, and reviewing registration documentation guidelines are some initial examples of how to apply the social model and UD directly to the service unit.

\section{Conclusion}

Services for disabled students in US universities are evolving. Fuelled by antidiscrimination legislation, these services began by accommodating the 'deficiencies' of disabled students; but now, they are identifying the campus environment as deficient and exclusive for disabled people. In a small number of services, a quiet revolution is taking shape; they are becoming proactive, campaigning for access, anticipating inaccessibility, educating their campuses about inclusion and their faculty about inclusive course and curriculum design. The social model of disability is the catalyst for this revolution.

The theoretical importance of this phenomenon is considerable and the consequences will substantially affect the lives of disabled students as campuses become more inclusive and the necessity to accommodate is reduced. Although this study focused on students with disabilities there is a potential for this to have an impact on a broader range of students (Higbee, Schultz and Goff, 2010).

The practical implications of the changes evidenced by this research are: first, that the services are becoming more outward-looking, expecting the university to change instead of the student; second, that the relationships with stakeholders are shifting, moving the emphasis from a medical model approach to a social model, regarding documentation and accommodations; third, that the responsibility for access is widening, so that the service is not seen as the retrospective solver of problems but a collaborator in the negotiation towards better access; and, finally, that an awareness of the social model and tools for implementing it, like UD, is increasing.

\section{References}

AHEAD (2004-2012) 'AHEAD: Association on Higher Education and Disability', Huntersville, NC: AHEAD, at www.ahead.org/ (accessed: 26 June 2012).

AHEAD (2012) 'Supporting Accommodation Requests: Guidance on Documentation Practices - April 2012', Huntersville, NC: AHEAD, at www.ahead.org/resources/ documentation_guidance (accessed: on 27 June 2012). 
Aune, B. (1998) 'Higher Education and Disability in the United States of America: The Context, a Comprehensive Model, and Current Issues', in A. Hurst (ed.) Higher education and disabilities: International approaches, Aldershot, UK: Ashgate.

Barnes, C. (2000) 'A Working Social Model? Disability, Work and Disability Politics in the 21st Century', Critical Social Policy, 20, 441-57.

Behling, K. and Hart, D. (2008) 'Universal Course Design: A Model for Professional Development', in S. E. Burgstahler and R. C. Cory (eds) Universal Design in higher education: From principles to practice, Cambridge, MA: Harvard Education Press.

Bloch, A. (2004) 'Doing Social Surveys', in C. Seale (ed.) Researching society and culture, London: SAGE Publications.

Block, L. S., Loewen, G. and Kroeger, S. (2006) 'Acknowledging and Transforming Disabling Environments in Higher Education: AHEAD's Role', Journal of Postsecondary Education and Disability Special Issue: Universal Design in Higher Education, 19, 2: 117-23.

Bowe, F. G. (2000) Universal Design in education: Teaching nontraditional students, Westport, CT, and London: Bergin and Garvey.

Burgstahler, S. E. (2008a) 'Universal Design in Higher Education', in S. E. Burgstahler and R. C. Cory (eds) Universal Design in higher education: From principles to practice, Cambridge, MA: Harvard Education Press.

Burgstahler, S. E. (2008b) 'Universal Design of Instruction: From principles to practice', in S. E. Burgstahler and R. C. Cory (eds) Universal Design in higher education: From principles to practice, Cambridge, MA: Harvard Education Press.

Burgstahler, S. E. (2008c) 'Promoters and Inhibitors of Universal Design in Higher Education', in S. E. Burgstahler and R. C. Cory (eds) Universal Design in higher education: From principles to practice, Cambridge, MA: Harvard Education Press.

Burgstahler, S. E. and Cory, R. C. (2008) Universal Design in higher education: From principles to practice, Cambridge, MA: Harvard Education Press.

Durre, I., Richardson, M., Smith, C., Shulman, J. A. and Steele, S. (2008) 'Universal Design of Instruction: Reflection of Students', in S. E. Burgstahler and R. C. Cory (eds) Universal Design in higher education: From principles to practice, Cambridge, MA: Harvard Education Press.

Embry, P. B., Parker, D. R., McGuire, J. M. and Scott, S. S. (2005) 'Postsecondary Disability Service Providers' Perceptions About Implementing Universal Design for Instruction (UDI)', Journal of Postsecondary Education and Disability, 18, 34-44.

Finn, D. E., Evans Getzel, E., Asselin, S. B. and Reilly, V. (2008) 'Implementing Universal Design: Collaborations across Campus', in S. E. Burgstahler and R. C. Cory (eds) Universal Design in higher education: From principles to practice, Cambridge, MA: Harvard Education Press.

Gibbs, D. (2004) 'Social Model Services: An Oxymoron?’, in C. Barnes and G. Mercer (eds) Disability policy and practice: Applying the social model, Leeds: The Disability Press.

Gillman, M. (2004) 'Diagnosis and Assessment in the Lives of Disabled People: Creating Potentials/Limiting Possibilities?', in J. Swain, S. French, C. Barnes and C. Thomas (eds) Disabling barriers - Enabling environments (2nd edition), London: SAGE Publications.

Hahn, H. (1985) 'Toward a Politics of Disability: Definitions, Disciplines, and Policies', Stockholm, Sweden: Independent Living Institute, at www.independentliving.org/ docs4/hahn2.html (accessed: 15 March, 2008). 
Higbee, J. L., Schultz, J. L. and Goff, E. (2010) 'The pedagogy of inclusion: Integrated multicultural instructional design', Journal of College Reading and Learning, 41, 1: 49-66.

Hurst, A. (1998) Higher education and disabilities: International approaches, Aldershot, UK: Ashgate.

Jarrow, J. (1993) 'Beyond ramps: New ways of viewing access', in Kroeger, S. and Schuck, J. (eds) Responding to Disability Issues in Student Affairs (New Directions for Student Services, no. 64), San Francisco: Jossey-Bass.

Jenner, C. (2008) 'A Change Process for Creating a Universally Designed Campus', in S. E. Burgstahler and R. C. Cory (eds) Universal Design in higher education: From principles to practice, Cambridge, MA: Harvard Education Press.

Kurth, N. and Mellard, D. (2006) 'Student Perceptions of the Accommodation Process in Postsecondary Education', Journal of Postsecondary Education and Disability, 19: 71-84.

Kroeger, S. and Schuck, J. (1993) 'Moving Ahead: Issues, Recommendations and Conclusions', in Kroeger, S. and Schuck, J. (eds) Responding to Disability Issues in Student Affairs (New Directions for Student Services, no. 64), San Francisco: Jossey-Bass.

Mason, J. (2002) Qualitative researching, London: Sage.

Mercer, G. (2004) 'User-Led Organisations: Facilitating Independent Living', in J. Swain, S. French, C. Barnes and C. Thomas (eds) Disabling barriers - Enabling environments (2nd edition), London: SAGE Publications.

McGuire, J. M., Scott, S. S. and Shaw, S. F. (2003) 'Universal Design for Instruction: The Paradigm, Its Principles, and Products for Enhancing Instructional Access', Journal of Postsecondary Education and Disability, 17, 1: 11-21, at www.eric.ed.gov/PDFS/ EJ875999.pdf (accessed: 23 November 2012).

Oliver, M. (1996) Understanding disability: From theory to practice, London: Macmillan Press.

Punch, K. (1998) Introduction to social research: Quantitative and qualitative approaches, London: SAGE.

The Center for Universal Design (1997) 'The Principles of Universal Design, Version 2.0', Raleigh, NC: North Carolina State University, at www.ncsu.edu/project/design-projects/ udi/center-for-universal-design/the-principles-of-universal-design/ (accessed: 27 June 2012).

Union of the Physically Impaired Against Segregation (UPIAS) (1974/1976) Union of the physically impaired against segregation: Policy statement, London: UPIAS, at www. leeds.ac.uk/disability-studies/archiveuk/UPIAS/UPIAS.pdf (accessed: 23 November 2012).

University of Arkansas at Little Rock (n.d.) Universal Design, Little Rock, AR: University of Arkansas at Little Rock, at http://ualr.edu/pace/index.php/home/hot-topics/ud (accessed: 27 June, 2012). 


\section{Appendix 1 - The questionnaire}

\section{Services for Students with Disabilities in Higher Education}

This questionnaire has 8 parts.

\section{Part 1. Introduction}

This survey will ask various questions about the service you provide to students with disabilities at your institution. To begin there will be a few introductory questions. The results will be anonymised. Please type answers following each question.

1. What is the total population of students at your Higher Education Institution? Answer:

2. How many faculty (Professors) are employed at your institution? Answer:

3. What is the full name of your office or service?

Answer:

4. How many staff do you employ to serve students with disabilities? Answer:

5. How many students with disabilities are currently registered with your service?

Answer:

6. How many students are registered with your service in each of the categories listed below?

a. Physical Disability - answer:

b. Sensory Disability - answer:

c. Learning Disability - answer:

d. Attention Deficit Hyperactivity Disorder - answer:

e. Mental Health/Psychiatric Disability - answer:

f. Other category (if these do not match yours) answer: 
7. Does your service have a published mission statement or value statement? (Yes or No)

Answer:

Please paste your mission statement or vision statement below.

Paste here:

\section{Part 2. Service philosophy}

The following questions will probe the philosophy of your service.

1. When it comes to serving students with disabilities would you say you apply the letter of the law (Section 504) or do you take a different view? (please comment on your answer)

Answer:

2. Are you aware of the social model of disability (or socio-political/ interactional model of disability)? (Yes or No)

Answer:

If you answered no please go to questions 6 and 7

3. Please tell me what your understanding of the social model of disability is. Answer:

4. Has the social model of disability been reflected in your service provision philosophy? (Yes or no)

Answer:

If you answered yes please go to Question 5, if you answered no please go to questions 6 and 7.

5. Please explain how the social model has informed your service philosophy. Answer:

6. Please explain why the social model has not informed your service philosophy. Answer:

7. What are the principal factors underpinning your university's framework for providing accommodations for students with disabilities?

Answer: 


\section{Part 3. Service philosophy continued}

The following questions will probe the development of your service according to your service philosophy.

1. Has your philosophy of service provision for students with disabilities changed over recent years? (Yes or No)

Answer:

If you answered Yes please go to question 2, if you answered No please go to question 3

2. If yes, how has it changed?

Answer:

Go to question 4

3. If no, why not?

Answer:

4. What would you say are the principal factors that have initiated this change? Answer:

\section{Part 4. Universal Design}

This section will explore whether you have used Universal Design Principles as part of the philosophy of your service.

1. How would you define the concept of Universal Design (UD)?

Answer:

2. Has Universal Design been a part of your mission/objectives? (yes or no) Answer:

3. When was this introduced into your service objectives?

Answer:

4. How do you see this fitting into your service philosophy?

Answer:

5. How does UD fit into a social model of disability perspective?

Answer: 
6. Does UD diverge from the social model of disability? In what respects? Answer:

7. What have been the biggest impacts that introducing UD into your service has made?

Answer:

\section{Part 5. Service aspects}

This section explores how the changes that you have made in your service philosophy and provision in recent years have impacted on different service aspects.

For questions 1-9 of this section please answer yes or no and then comment on how you changed the service or why you didn't.

1. Did you change language used in publications or website?

Answer:

2. Did you change the type of services you provide?

Answer:

3. Did you change the documentation of disabilities required?

Answer:

4. Did you change your interactions with student users?

Answer:

5. Did you change your interactions with faculty users?

Answer:

6. Did you change your impact on the University's built environment?

Answer:

7. Did you change your influence on instructional materials used by faculty?

Answer:

8. Did you change your impact on wider University policies and practices?

Answer:

9. Did you change anything else not covered here?

Answer: 
10. Did the changes above happen:
a. All at once
b. As part of a phased plan
c. Piecemeal

Answer:

\section{Part 6. Transition}

This is the last theme of the questionnaire and it will explore the recent changes that you have made to your service and how they have impacted on different service users.

1. What was the process involved in transitioning from one service philosophy to a new one in recent years?

Answer:

2. Please explain how students have responded to recent changes in disability services.

Answer:

3. Please explain how the faculty (Professors) have responded to recent changes in disability services.

Answer:

4. Please explain how senior administrators have responded to recent changes in disability services.

Answer:

5. Please explain how staff in your service have responded to recent changes in disability services.

Answer:

6. Please explain whether you experienced difficulties financing the changes. Answer:

7. If you experienced other significant difficulties during this process please explain them here.

Answer: 


\section{Part 7. Transition continued}

8. What do you consider are the most successful outcomes of recent policy developments for students with disabilities in your university?

Answer:

9. Do you see/have you seen the role of your service changing as you implement more of your objectives and come closer to the goals you have defined? (yes or no)

Answer:

If yes, how?

Answer:

10. How would you like to see your service developing in the future?

Answer:

11. What, if any, do you consider to be the principal barriers to the further development of services for students with disabilities in your university?

Answer:

12. Do you think a fully inclusive educational environment that accommodates the needs of all students with disabilities in US universities is possible? (yes or no)

Answer:

Please explain your answer:

13. If you were to advise your counterparts at another Higher Education Institution about the changes you have implemented in your service, what would be your main recommendations?

Answer:

\section{Part 8}

Thank you for your participation in this survey, please answer these two final questions.

I am interested to know whether you feel there were any important issues that I didn't cover in this survey.

Answer: 
Having completed the survey, you can decide whether you would like your institution to remain anonymous in the findings of this research. If you choose anonymity, I (Heather Mole) will be the only person who knows the identity of participating institutions. Please choose one of the 2 options below:

a. I would like my institution to be anonymous in the Masters dissertation/ thesis and any further publications resulting from this study.

b. I am happy for the name of my institution to be included in the Masters dissertation/thesis and any further publications resulting from this study.

Answer:

Thank you very much for completing the survey.

I will disseminate a summary of the findings to participating institutions as soon as they are ready.

Don't hesitate to get in touch with me if you want to make a comment.

Heather Mole 